Arq. Bras. Med. Vet. Zootec., v.69, n.4, p.948-954, 2017

\title{
Caracterização histomorfológica do sistema tegumentar auricular de cateto (Pecari tajacu Linnaeus, 1758)
}

\author{
[Histomorphological characterization of collared peccary (Pecari tajacu Linnaeus, 1758) \\ ear integumentary system]
}

\author{
A.A. Borges, F.V.F. Bezerra, F.N Costa, L.B. Queiroz Neta, M.V.O. Santos, \\ M.F. Oliveira, A.R. Silva, A.F. Pereira ${ }^{*}$
}

Universidade Federal Rural do Semi-Árido - UFERSA - Mossoró, RN

\begin{abstract}
RESUMO
A criopreservação de tecido somático derivado da pele de catetos consiste numa alternativa para a conservação da biodiversidade por meio da associação com a transferência nuclear. Nesse contexto, a manipulação de tecidos da pele é uma etapa crucial para o sucesso dessa biotécnica. Portanto, o objetivo do presente estudo, foi caracterizar o sistema tegumentar auricular periférico de catetos, visando aprimorar a conservação tecidual. Para tanto, fragmentos auriculares de oito animais foram avaliados quanto às camadas teciduais, aos componentes, à atividade proliferativa e à viabilidade metabólica, usando-se as colorações hematoxilina-eosina e tricrômico de Gomori, quantificação de AgNORs e microscopia eletrônica de transmissão. Assim, tamanhos de $104,2 \mu \mathrm{m}$ e $222,6 \mu \mathrm{m}$ foram observados para epiderme e derme, com uma proporção volumétrica de $36,6 \%$ e $58,7 \%$, respectivamente. Além disso, na epiderme, foram evidenciadas as camadas basal $(22,5 \mu \mathrm{m})$, intermediárias $(53,5 \mu \mathrm{m})$ e córnea $(28,2 \mu \mathrm{m})$, com valores médios de 65,3 células epidermais, 43,4 melanócitos e 14,8 halos perinucleares. Já a derme apresentou 127 fibroblastos, com 2,5 AgNORs/nucléolo. Adicionalmente, a atividade metabólica foi de 0,243 . Em conclusão, o sistema tegumentar auricular periférico de catetos possui algumas marcantes variações em relação a outros mamíferos, quanto ao número de camadas e espessura da epiderme, quantidade de células epidermais, melanócitos e parâmetros proliferativos.
\end{abstract}

Palavras-chave: animais silvestres, avaliação histológica, quantificação celular

\begin{abstract}
The cryopreservation of somatic tissue derived from skin of collared peccaries is an alternative for biodiversity conservation through association with nuclear transfer. In this context, tissue manipulation of skin is a critical step for the success of this biotechnique. Therefore, the aim was to characterize the peripheral ear integumentary system derived from collared peccaries, directing to improve tissue conservation. Thus, ear fragments of eight animals were evaluated for tissue layers, components, proliferative activity and metabolic viability, using hematoxylin-eosin and Gomori Trichrome, AgNORs quantification and transmission electronic microscopy. Hence, sizes of $104.2 \mu \mathrm{m}$ and $222.6 \mu \mathrm{m}$ were observed in the epidermis and dermis, with a volumetric ratio of $36.6 \%$ and $58.7 \%$, respectively. Moreover, basal layer $(22.5 \mu \mathrm{m})$, intermediate $(53.5 \mu \mathrm{m})$ and cornea $(28.2 \mu \mathrm{m})$, with mean values of 65.3 epidermal cells, 43.4 melanocytes and 14.8 perinuclear halos were evidenced in the epidermal. Already the dermis has 127 fibroblasts with 2.5 AgNORs/nucleolus. Additionally, the metabolic activity was 0.243. In conclusion, the peripheral ear integumentary system derived from collared peccaries possessed some important variations compared to other mammals, as the number of layers and thickness of the epidermis, number of epidermal cells, melanocytes and proliferative parameters.
\end{abstract}

Keywords: wild animals, histological evaluation, cell quantification

Recebido em 14 de outubro de 2016

Aceito em 19 de outubro de 2016

*Autor para correspondência (corresponding author)

E-mail: alexsandra.pereira@ufersa.edu.br 


\section{INTRODUÇÃO}

$\mathrm{O}$ cateto $(P$. tajacu $)$, pertencente à família Tayassuidae, subordem Suiformes, ordem Artiodactyla (Groves e Grubb, 1993), é uma espécie com comprimento de $84-106 \mathrm{~cm}$, altura de $30-50 \mathrm{~cm}$ e peso de $18-30 \mathrm{~kg}$ (Desbiez et al., 2009). Em geral, os animais possuem pelagem castanho-cinza com uma faixa branca no pescoço, uma glândula próxima à cauda e são considerados bons dispersores de sementes (Morales et al., 2015). Também como representantes da família Tayassuidae, tem-se o queixada (Tayassu pecari) e o tágua (Catagonus wagneri), os quais, ao contrário dos catetos, encontram-se em níveis populacionais decrescentes (International Union for Conservation of Nature, 2016).

Além disso, a família Tayassuidae está relacionada com a Suidae, uma vez que pertencem à mesma ordem (Bosma et al., 2004), resultando essa proximidade entre as espécies em um maior interesse pelos catetos, uma vez que a pele de suínos é a mais comumente utilizada como modelo na medicina regenerativa humana (Morimoto et al., 2015). Adicionalmente, os catetos podem ser empregados como modelo experimental (Argôlo-Neto et al., 2016) para espécies da mesma família com níveis populacionais reduzidos. Ainda, os catetos, em virtude da apreciação de sua carne e do couro, podem ser empregados na criação comercial pela produção e renda de produtores rurais, especialmente em regiões que não possuem condições de suportar as necessidades domésticas (Santos et al., 2009).

Assim, entre as estratégias de conservação dessa espécie, a criopreservação de germoplasma pela preservação de tecido somático derivado da pele consiste em uma alternativa interessante, uma vez que permite maior facilidade na obtenção e ampla amostragem por população (León-Quinto et al., 2009). Além disso, tecidos somáticos criopreservados são fontes importantes de células doadoras de núcleo para a transferência nuclear ou clonagem. Contudo, há poucas informações sobre as características do sistema tegumentar auricular de catetos, o que dificulta o estabelecimento de protocolos de manipulação e criopreservação de maneira objetiva. O esclarecimento dos diferentes componentes da pele da região auricular poderia favorecer o uso de agentes específicos tanto na criopreservação quanto no cultivo in vitro desses tecidos (Santos et al., 2016), uma vez que componentes da pele diferem em sua capacidade de transporte (Grabau et al., 1995). Adicionalmente, pesquisas voltadas para identificação do tecido tegumentar poderiam proporcionar um conhecimento sobre a morfofisiologia dessa espécie e daquelas filogeneticamente próximas.

Portanto, o presente trabalho objetivou descrever o sistema tegumentar da região auricular periférica de catetos, usando técnicas histológicas e ultraestruturais.

\section{MATERIAL E MÉTODOS}

Todos os procedimentos usados no presente estudo foram aprovados pelo Comitê de Ética de Uso de Animais da Universidade Federal Rural do Semiárido (Ceua/Ufersa, $\mathrm{n}^{\circ}$. 23091.001072/2015-92), em conformidade com o Instituto Chico Mendes de Conservação da Biodiversidade (ICMBio, $n^{\circ}$. 48633-1). Para tanto, foi usado um total de oito animais (três a seis meses), entre machos e fêmeas, provenientes do Centro de Multiplicação de Animais Silvestres (Cemas/Ufersa, $n^{\circ}$. Ibama 1478912). As amostras de pele da região auricular periférica foram recuperadas de maneira asséptica, de acordo com o sistema de manejo de identificação dos indivíduos, e fragmentos $(9,0$ $\mathrm{mm}^{3}$ ) foram submetidos às diferentes análises.

Assim, para a histologia clássica e a quantificação de regiões argirofílicas organizadoras nucleorares (AgNORs), fragmentos foram fixados em $4 \%$ de paraformaldeído, seccionados em 5,0 $\mathrm{\mu m}$, corados com hematoxilina-eosina (HE), tricrômico de Gomori ou marcados com AgNOR e visualizados usando-se microscopia de luz (Leica DM500, Leica Microsystems, Alemanha) com câmara acoplada (Leica ICC50 HD, Leica Microsystems, Alemanha) para a obtenção das imagens. Para a avaliação da HE, 20 campos aleatórios (magnitude 40×) foram selecionados em cada lâmina e analisados usando-se o software Image $\mathrm{J}$ (US National Institutes of Health, EUA) para a quantificação das células, halos perinucleares e proporção volumétrica da epiderme e derme, segundo a fórmula de Sharpe et al. (1989): 
proporção volumétrica $=$ somatório de sobreposição da estrutura aos pontos * 100/total de pontos contados.

Já para a avaliação do tricrômico de Gomori, imagens foram obtidas quanto à identificação de fibras colágenas e fibroblastos. Para a análise da atividade proliferativa, foram contabilizados 100 núcleos (magnitude 100×) em lâminas da marcação de AgNORs e avaliados conforme Yang et al. (2013).

Para a microscopia eletrônica de transmissão, fragmentos foram fixados em glutaraldeído 2,5\% diluído em tampão fosfato $0,1 \mathrm{M}(\mathrm{pH} 7,3)$, pósfixados em tetróxido de ósmio $2 \%$ e contrastados com acetato de uranila sob câmara escura. $\mathrm{Na}$ desidratação, foram realizados banhos crescentes de etanol, óxido de propileno, óxido de propileno-resina Spurr e somente resina. Após a inclusão e polimerização da resina, os blocos foram seccionados em $60 \mathrm{~nm}$, contrastados com acetato de uranila $2 \%$ e em citrato de chumbo $0,5 \%$ para posterior visualização em microscopia (EM-94S2, Carl Zeiss, Alemanha).

Para a avaliação metabólica, fragmentos teciduais foram analisados pelo método calorimétrico brometo de 3-[4,5-dimetiltiazol-2il]-2,5-difeniltetrazólio (MTT), de acordo com Boekema et al. (2015). Brevemente, amostras foram incubadas em meio essencial mínimo por $30 \mathrm{~min}$ a $37^{\circ} \mathrm{C}$ e, posteriormente, em solução de MTT $(2 \mathrm{mg} / \mathrm{mL})$ por três horas a $37^{\circ} \mathrm{C}$. Os cristais formados após a incubação foram dissolvidos em dimetilsulfóxido e, em seguida, mensurações foram realizadas usando-se uma absorbância de 595nm. Finalmente, os dados foram apresentados como média \pm desviopadrão e avaliados descritivamente.

\section{RESULTADOS E DISCUSSÃO}

Inicialmente, a pele da região auricular periférica de catetos apresentou uma estrutura histológica semelhante ao padrão de mamíferos (Junqueira e Carneiro, 2013) quanto à divisão em duas camadas, epiderme e derme (Fig. 1A) com diferenças celulares e estruturais visualizadas entre elas, evidenciando suas origens embrionárias distintas, ectodérmica e mesodérmica, respectivamente. Além disso, a epiderme e a derme apresentaram uma proporção volumétrica de $36,6 \%$ e $58,7 \%$, respectivamente. Em uma classificação apresentada por Grabau et al. (1995) para mamíferos como suínos, murinos e primatas, a epiderme pode ser dividida em epiderme viável, que contém células nucleadas (camada granular, espinhosa e basal), e em não viável, que consiste de uma camada não nucleada queratinizada (camada córnea). Em catetos, a denominação viável foi identificada pelas camadas basal e intermediárias (Fig. 1B), as quais foram caracterizadas como mitogênicas. Já a epiderme não viável de catetos foi identificada como sendo a camada córnea (Fig. 1B), a qual possuía uma forte queratinização. Todas essas características observadas na epiderme foram similares aos demais mamíferos (Grabau et al., 1995).

Diferenças quanto ao número de camadas da epiderme podem ser evidenciadas em mamíferos. Em catetos, apenas três camadas foram visíveis na epiderme basal $(22,5 \mu \mathrm{m})$, nas intermediárias $(53,5 \mu \mathrm{m})$ e na córnea $(28,2 \mu \mathrm{m})$, apresentando um tamanho total de $104,2 \mu \mathrm{m}$ (Fig. 2) e com tecido epitelial estratificado pavimentoso queratinizado. Similaridade dessa divisão de camadas da epiderme também foi descrita em cervídeos (Axis axis, Nagaraju et al., 2012). Em mamíferos, em geral, as camadas da epiderme podem ser divididas em córnea, lúcida, granulosa, espinhosa e basal (Junqueira e Carneiro, 2013) e esse padrão também pode ser observado em suínos (Jacobi et al., 2005). Adicionalmente, Grabau et al. (1995) apresentaram o tamanho total da epiderme de alguns mamíferos e observaram camundongos (Mus musculus) com 46,7 $\mu \mathrm{m}$, ratos (Rattus norvegicus) com 86,0 $\mu \mathrm{m}$, cobaias (Cavia

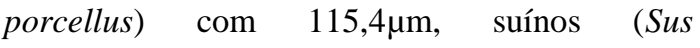
domesticus) com 79,5 $\mu \mathrm{m}$ e macacos (Macaca mulatta) com $35,7 \mu \mathrm{m}$. Em suínos Yucatan, a epiderme foi mensurada em 84,0 $\mu \mathrm{m}$, em um valor menor ao observado na epiderme de catetos $(104,2 \mu \mathrm{m})$. Contudo, variações dessa espessura também são esperadas em raças da mesma espécie (Eggleston et al., 2000), e talvez em outras raças suínas, os valores sejam mais similares aos catetos. 


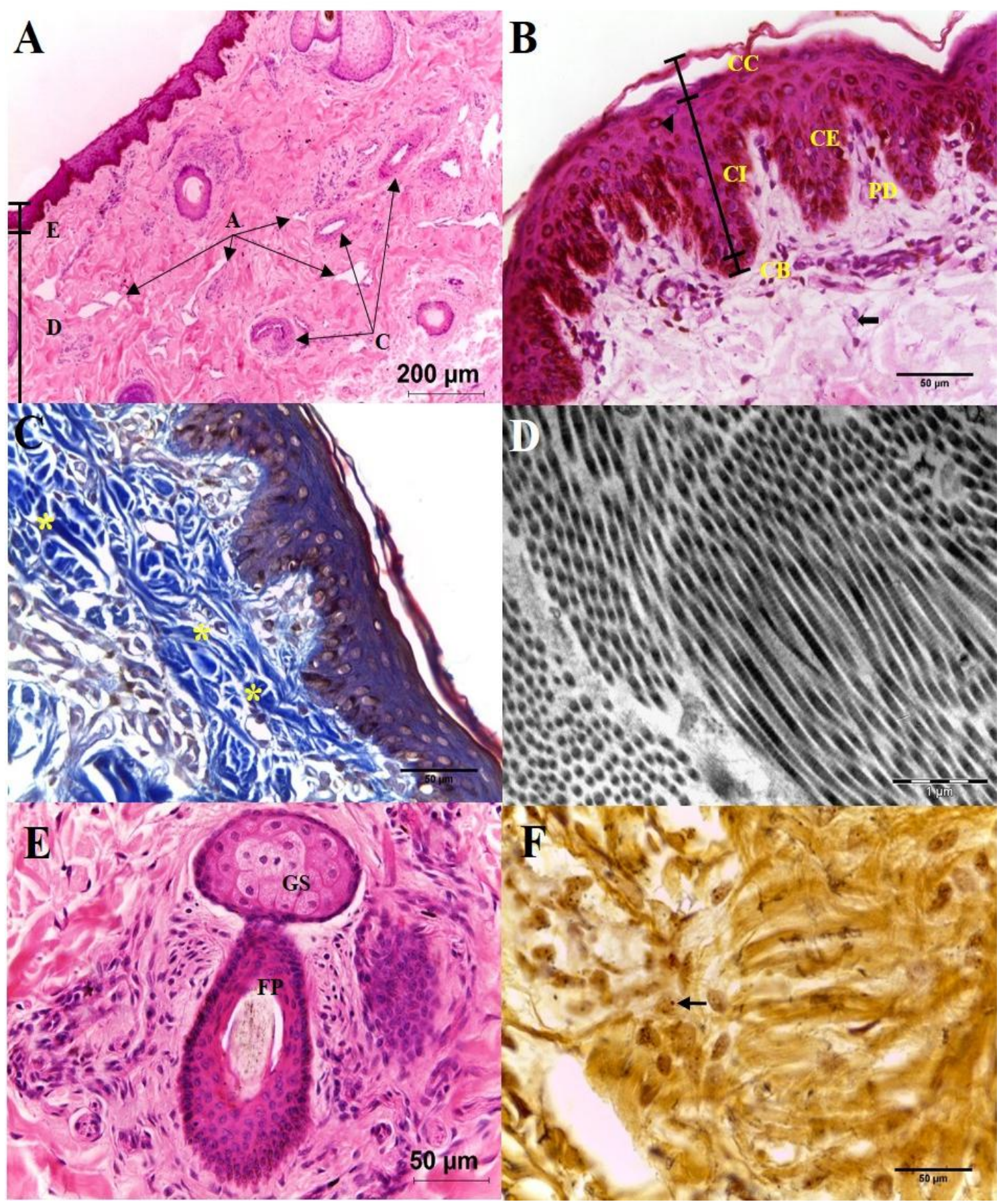

Figura 1. Fotomicrografias da pele de catetos (P. tajacu). A: Cútis corada com HE. Epiderme (E), derme papilar (D), arteríola (A), capilares sanguíneos (C). B: Corte perpendicular de pele corado com HE. Camada córnea (CC), camadas intermediárias (CI), camada basal (CB), fibroblastos presentes na derme (seta), halos perinucleares (triângulo), (CE) cristas epiteliais, (PD) papilas dérmicas. C: Pele corada com tricrômico de Gomori. Fibras colágenas (*). D: Micrografia eletrônica de transmissão de fibras colágenas em cortes transversais e longitudinais. E: Estrutura do folículo piloso (FP) e glândula sebácea (GS). F: Quantificação de AgNORs. Pontos marcados do nucléolo (seta). 


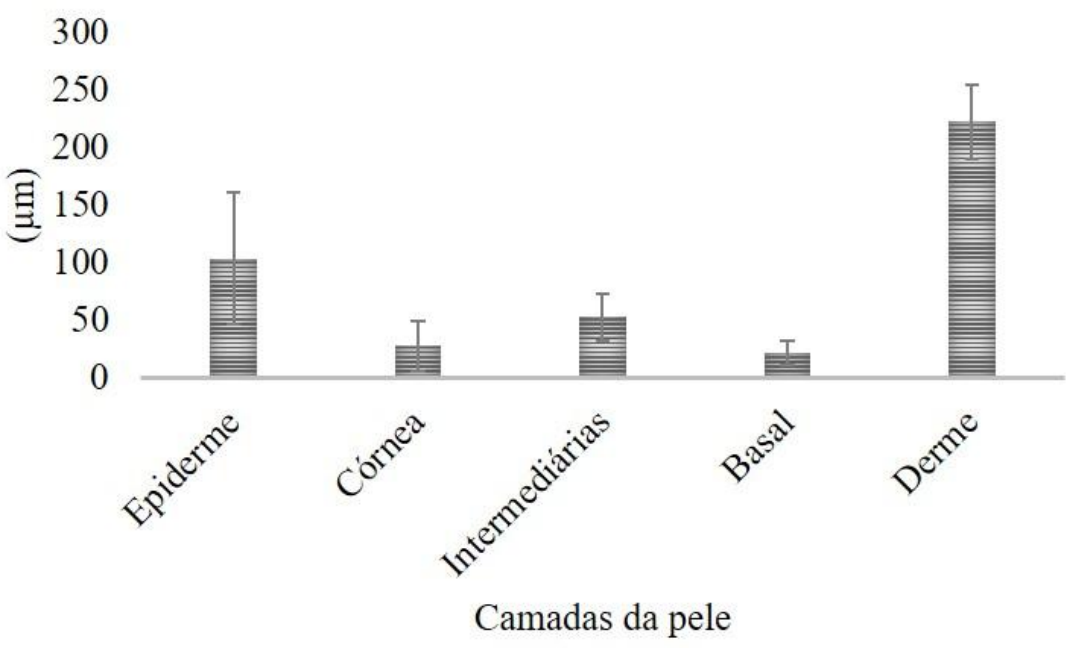

Figura 2. Mensuração dos tamanhos das camadas da pele e da epiderme da região auricular de catetos $(P$. tajacu) usando-se coloração de hematoxilina-eosina.

Além disso, a camada córnea apresentou células pavimentosas características dessa camada já evidenciada em diferentes espécies (Doran et al., 1980). Já como camadas intermediárias, foram consideradas a granulosa e a espinhosa, as quais foram de difícil distinção, conforme também observado em pacas (Cuniculus paca) por Isola et al. (2013) e em suínos por Turner et al. (2014).

Ainda, o sistema tegumentar auricular periférico de catetos apresentou algumas peculiaridades quando foi comparado ao dos demais mamíferos, especialmente quanto ao número de células presentes e aos parâmetros proliferativos quantificados por AgNOR. Especificamente quanto à camada basal (Fig. 1B), esta apresentou células cúbicas com núcleos esféricos e forte coloração em virtude da alta quantidade de melanina. A quantidade de melanócitos evidenciada na camada basal foi de 43,4 (Tab. 1) e a alta produção de melanina já era esperada em razão da coloração escura que os catetos possuem. Para suínos Yorkshire, a quantidade média de melanócitos é de 6-15 (Navarro et al., 2001).

Independentemente das camadas teciduais, variações nas camadas de células epidermais dentro das camadas basal, intermediárias e córnea puderam ser observadas. Adicionalmente, foram evidenciadas quatro camadas de células epidermais nos catetos, resultado que difere de pacas, com seis camadas (Isola et al., 2013), cervídeos, com três camadas, e bovinos, com cinco camadas (Nagaraju et al., 2012), mas que é similar aos suínos (Monteiro-Riviere et al., 1990) e aos caprinos (Nagaraju et al., 2012).

Tabela 1. Valores médios de diferentes células da epiderme derivada da região auricular de catetos (P. tajacu) usando a coloração de hematoxilinaeosina

\begin{tabular}{lcc}
\hline Parâmetros & $\begin{array}{c}\text { Média } \pm \text { desvio } \\
\text { padrão }\end{array}$ & Variação \\
\hline Células epidermais & $65,3 \pm 18,3$ & $14-193$ \\
Melanócitos & $43,4 \pm 16,4$ & $10-94$ \\
Fibroblastos & $127,0 \pm 41,1$ & $54-275$ \\
\hline
\end{tabular}

Quanto à derme, esta apresentou um tamanho de 222,6 $\mu \mathrm{m}$, com os seguintes apêndices cutâneos: arteríolas e capilares sanguíneos (Fig. 1A), fibras colágenas (Fig. 1C), folículo piloso observado na papila dérmica e glândula sebácea localizada abaixo do folículo (Fig. 1E). Essa localização da glândula sebácea se assemelhou à identificada em cervídeos (Nagaraju et al., 2012), pacas (Isola et al., 2013) e suínos (Vardaxis et al., 1997). Na coloração com tricrômico de Gomori, foram observadas fibras colágenas de espessura aparentemente homogênea. Já por microscopia eletrônica de transmissão, foi possível observar cada fibrila formada por bandas claras e escuras, delimitadas por estriações transversais com espaço entre elas constituído de matriz extracelular (Fig. 1D). 
Além disso, a derme de catetos apresentou um alto perfil proliferativo evidenciado pela quantificação de AgNORs (Tab. 2). Especificamente, as regiões organizadoras de nucléolo (NORs) são unidades estruturais e funcionais do nucléolo, nas quais estão localizadas as proteínas necessárias para a síntese de RNA ribossomal e, por isso, a quantificação de AgNORs evidencia a atividade transcricional e a proliferação celular (Mondal et al., 2015). Nesse sentido, a avaliação dos padrões de AgNORs para um epitélio saudável e sem nenhum tratamento permitirá em catetos a padronização para futuras análises. O número de AgNORs em catetos $(2,48$ com área de $1,15 \mu \mathrm{m}$, Tab. 2) foi similar ao evidenciado em epitélio humano (Jaafari-Ashkavandi e Fatemi, 2013), no qual esses autores obtiveram um número de 2,38 AgNORs numa área de 1,36 $\mu \mathrm{m}$. Para suínos, o número de AgNORs foi de 1,22, e a área foi de

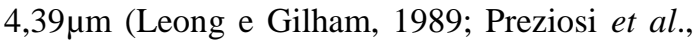
2000). Adicionalmente, os valores relacionados à área do AgNOR foram de acordo com a biogênese do ribossoma (Derenzini, 2000).

Tabela 2. Avaliação da atividade proliferativa na derme da região auricular de catetos ( $P$. tajacu) usando a quantificação de AgNORs

\begin{tabular}{|c|c|c|c|c|}
\hline \multicolumn{5}{|c|}{ Quantificação de AgNOR (média \pm desvio padrão) } \\
\hline Número & & Área $(\mu \mathrm{m})$ & & \\
\hline AgNORs & AgNORs/núcleo & AgNORs & Núcleo & AgNOR/ núcleo \\
\hline $2,48 \pm 0,95$ & $0,02 \pm 0,01$ & $1,15 \pm 0,60$ & $14,47 \pm 6,09$ & $0,14 \pm 0,44$ \\
\hline
\end{tabular}

A atividade metabólica pelo ensaio de MTT permitiu inferir um padrão de 0,243 para a pele não submetida a nenhum tratamento nos catetos avaliados. Essa informação poderá ser útil em outras análises para quantificação de resposta metabólica após o processo de criopreservação. Além disso, o número de halos perinucleares evidenciados no tecido não submetido à criopreservação foi de 14,8 $\pm 10,1$ (0-56). Esses halos são estruturas que sinalizam o início da apoptose e são formados quando o núcleo é separado do citoplasma (Boekema et al., 2015), o que caracteriza um parâmetro também interessante na análise de um protocolo de conservação tecidual.

\section{CONCLUSÃO}

O presente estudo caracterizou-se como o primeiro trabalho de descrição da estrutura histológica do sistema tegumentar da região auricular periférica de catetos. Apesar de algumas similaridades, há parâmetros que variam marcadamente entre as espécies mamíferas e os catetos, especialmente quanto ao número de camadas e à espessura da epiderme, à quantidade de células epidermais e de melanócitos e à atividade proliferativa. O conhecimento obtido permitirá o direcionamento de protocolos de conservação de tecido somático da pele, visando à clonagem nessa espécie e naquelas filogeneticamente próximas, bem como oferecerá informações sobre o desenvolvimento e o comportamento desse tecido.

\section{REFERÊNCIAS}

ARGÔLO-NETO, N.M.A.; FEITOSA, M.L.T.; SOUSA, S.S. et al. Isolation, expansion, differentiation and growth kinetics essay in mesenchymal stem cells culture from the bone marrow of collared peccaries (Tayassu tajacu). Acta Sci. Vet., v.44, p.1-11, 2016.

BOEKEMA, B.K.H.L.; BOEKESTIJN, B.; BREEDERVELD, R.S. Evaluation of saline, RPMI and DMEM/F12 for storage of split-thickness skin grafts. Burns, v.41, p.848-852, 2015.

BOSMA, A.A.; DE HAAN, N.A.; ARKESTEIJN, G.J.A. et al. Comparative chromosome painting between the domestic pig (Sus scrofa) and two species of peccary, the collared peccary (Tayassu tajacu) and the white-lipped peccary (T. pecari): a phylogenetic perspective. Cytogenet. Genome Res., v.105, p.115121,2004

DERENZINI, M. The AgNORs. Micron, v.31, p.117120,2000

DESBIEZ, A.L.J.; SANTOS, S.A.; KEUROGHLIAN, A.; BODMER, R.E. Niche partitioning among whitelipped peccaries (Tayassu pecari), collared peccaries (Pecari tajacu), and feral pigs (Sus scrofa). J. Mammal., v.90, p.119-128, 2009.

DORAN, T.I.; VIDRICH, A.; SUN, T.T. Intrinsic and extrinsic regulation of the differentiation of skin, corneal and esophageal epithelial cells. Cell, v.22, p.17-25, 1980 .

EGGLESTON, T.A.; ROACH, W.P.; MITCHELL, M.A. et al. Comparison of two porcine (Sus scrofa domestica) skin models for in vivo near-infrared laser exposure. Comp. Med., v.50, p.391-397, 2000. 
GRABAU, J.H.; DONG, L.; MATTIE, D.R. et al. Comparison of anatomical characteristics of the skin for several laboratory animals. ]s.1.]: Geo-Centers Inc Newton Centre, 1995. 35p.

GROVES, C.P.; GRUBB, P. The suborder Suiformes. In: OLIVER, W.L.R. (Ed.). Pigs, peccaries and hippos. Suíça: IUCN, The World Conservation Union, 1993. p.1-4.

INTERNATIONAL Union for Conservation of Nature: red list of threatened species. Gland: IUCN, 2016. Available in: 〈http:// www.iucnredlist.org >. Accessed in: 21 jun. 2016.

ISOLA, J.G.; MORAES, P.C.; RAHAL, S.C.; MACHADO, M.R. Morfologia, ultraestrutura e morfometria do tegumento da paca (Cuniculus paca Linnaeus, 1766) criada em cativeiro. Pesqui. Vet. Bras., v.33, p.674-682, 2013.

JAAFARI-ASHKAVANDI, Z.; FATEMI, F.S. Evaluation of proliferation activity in dysplastic and nondysplastic oral lichen planus through the analysis of argyrophilic nucleolar organizer regions. $J$. Craniofac. Surg., v.24, p.788-791, 2013.

JACOBI, U.; TOLL, R.; AUDRING, H. et al. The porcine snout-an in vitro model for human lips? Exp. Dermatol., v.14, p.96-102, 2005.

JUNQUEIRA, L.C.; CARNEIRO, J. Pele e anexos. In: JUNQUEIRA, L.C.; CARNEIRO, J. Histologia básica: texto \& atlas. Brasil: Guanabara Koogan, 2013. p.354-365.

LEÓN-QUINTO, T.; SIMON, M.A.; CADENAS, R. et al. Developing biological resource banks as a supporting tool for wildlife reproduction and conservation: the Iberian lynx bank as a model for other endangered species. Anim. Reprod. Sci., v.112, p.347-361, 2009.

LEONG, A.S.Y.; GILHAM, P. Silver staining of nucleolar organizer regions in malignant melanoma and melanotic nevi. Hum. Pathol., v.20, p.257-262, 1989.

MONDAL, N.K.; ROYCHOUDHURY, S.; RAY, M.R. Higher AgNOR expression in metaplastic and dysplastic airway epithelial cells predicts the risk of developing lung cancer in women chronically exposed to biomass smoke. J. Environ. Pathol. Toxicol. Oncol., v.34, p.35-51, 2015.

MONTEIRO-RIVIERE, N.A.; BRISTOL, D.G.; MANNING, T.O. et al. Interspecies and interregional analysis of the comparative histologic thickness and laser Doppler blood flow measurements at five cutaneous sites in nine species. J. Invest. Dermatol., v.95, p.582-586, 1990.
MORALES, J.C.G.; GUADARRAMA, V.M.F.; BLASIO, A.L. et al. Regionalización histológica de la glándula dorsal del pecarí de collar (Artiodactyla, Tayassuidae: Pecari tajacu). Cienc. Ergo-sum, v.22, p.225-232, 2015.

MORIMOTO, N.; MAHARA, A.; SHIMA, K. et al. The rapid inactivation of porcine skin by applying high hydrostatic pressure without damaging the extracellular matrix. Biomed. Res. Int., v.2015, p.1-9, 2015.

NAGARAJU, G.N.; PRASAD, R.V.; JAMUNA, K.V.; RAMKRISHNA, V. Histomorphological features in the differentiation of skin of spotted deer (Axis axis), Cattle (Bos indicus) and Goat (Capra hircus). Indian J. Vet. Anat., v.24, p.10-12, 2012.

NAVARRO, F.A.; STONER, M.L.; LEE, H.B. et al. Melanocyte repopulation in full-thickness wounds using a cell spray apparatus. J. Burn Care Res., v.22, p.41-46, 2001.

PREZIOSI, R.; SARLI, G.; MARCATO, P.S. Cell proliferation and apoptosis in the pathogenesis of oesophagogastric lesions in pigs. Res. Vet. Sci., v.68, p.189-196, 2000.

SANTOS, D.O.; MENDES, A.; NOGUEIRA, S.S.D.C.; NOGUEIRA FILHO, S.L.G. Criação comercial de caititus (Pecari tajacu): uma alternativa para o agronegócio. Rev. Bras. Saúde Prod. Anim., v.10, p.1-10, 2009.

SANTOS, M.L.T.; BORGES, A.A.; QUEIROZ NETA, L.B. et al. In vitro culture of somatic cells derived from ear tissue of collared peccary (Pecari tajacu Linnaeus, 1758) in medium with different requirements. Pesqui. Vet. Bras., v.36, p.1194-1202, 2016.

SHARPE, K.L.; EILER, H.; CULLEN, W.C.; HOPKINS, F.M. Morphometric analysis of collagen in gestational and retained bovine placentomes. Theriogenology, v.32, p.485-491, 1989.

TURNER, N.J.; PEZZONE, D.; BADYLAK, S.F. Regional variations in the histology of porcine skin. Tissue Eng. Part C Methods, v.21, p.373-384, 2014.

VARDAXIS, N.J.; BRANS, T.A.; BOON, M.E. et al. Confocal laser scanning microscopy of porcine skin: implications for human wound healing studies. $J$. Anat., v.190, p.601-611, 1997.

YANG, J.G.; DENG, Y.; ZHOU, L.X. et al. Overexpression of CDKN1B inhibits fibroblast proliferation in a rabbit model of experimental glaucoma filtration surgery when CDKN1B inhibits fibroblast proliferation. Invest. Ophthalmol. Vis. Sci., v.54, p.343-352, 2013. 